\title{
The safety of formoterol among patients with asthma using inhaled corticosteroids. Systematic review and meta-analysis
}

\author{
Roman Jaeschke ${ }^{1,2}$, Paul M. O’Byrne', Parameswaran Nair', Filip Mejza ${ }^{2,3}$, \\ Wiktoria Leśniak ${ }^{2,3}$, Jan Brożek ${ }^{2,3,4}$, Lehana Thabane $e^{5,6}$, Ji Cheng ${ }^{6}$, Małgorzata Bała ${ }^{2,3}$, \\ Holger J. Schünemann ${ }^{4,5,6}$, Malcolm R. Sears ${ }^{1}$, Gordon Guyatt ${ }^{1,5,7}$ \\ 1 Department of Medicine, McMaster University, Hamilton, ON, Canada \\ 2 Polish Institute of Evidence Based Medicine, Kraków, Poland \\ 3 Department of Internal Medicine, Jagiellonian University Medical College, Kraków, Poland \\ 4 Italian National Cancer Institute, Rome, Italy \\ 5 Department of Clinical Epidemiology and Biostatistics, McMaster University, Hamilton, ON, Canada \\ 6 Biostatistics Unit, Father Sean O'Sullivan Research Centre, St Joseph's Healthcare, Hamilton, ON, Canada \\ 7 CLARITY Research Group in the Department of Clinical Epidemiology and Biostatistics, McMaster University, Hamilton, ON, Canada
}

\section{KEY WORDS}

asthma, formoterol, hospitalizations, inhaled corticosteroids, mortality, safety
Correspondence to:

Roman Jaeschke, MD, PhD, 301 James Street South, Fontbonne Building, Room F506, Hamilton, ON, Canada, L8P3B6, phone: 001-905-521-6077, fax: 001-905-521-6068, e-mail: jaeschke@mcmaster.ca Received: October 3, 2008. Revision accepted: October 3, 2008. Declared conflict of interests. Pol Arch Med Wewn. 2008; 118 (11): $627-635$ Copyright by Medycyna Praktyczna, Kraków 2008

\section{ABSTRACT}

INTRODUCTION It has been postulated that inhaled long acting $\beta$-agonists (LABAs) when used as monotherapy in asthma may increase the incidence of asthma related deaths, intubations and hospitalizations, but concomitant use of inhaled corticosteroids (ICS) may modify this effect.

OBJECTIVES To assess the safety of formoterol in patients with asthma using ICS.

PATIENTS AND METHODS We conducted a systematic review and meta-analysis of parallel group, blinded, randomized controlled trials with at least 12 weeks of treatment examining the impact of twice a day formoterol on asthma-related and total morbidity and mortality in patients concurrently using ICS. Our main analysis considering impact of LABAs (salmeterol and formoterol) has already been published. In this report we present detailed information from studies investigating use of twice daily formoterol among patients receiving ICS.

RESULTS The search yielded 16 relevant studies included in this analysis. Among over 10,000 participants $(5,996$ taking formoterol with over 4,000 patient-years observation in formoterol groups) there were 2 asthma-related deaths (both in formoterol groups) and no asthma-related non-fatal intubations. The risk of asthma-related hospitalizations (odds ratio [OR] 0.59, 95\% $\mathrm{Cl} 0.37-0.93$ ) and asthma-related serious adverse events (mostly hospitalizations) [OR $0.58,95 \% \mathrm{Cl} 0.37-0.91$ ] were significantly lower in patients on formoterol and ICS compared to patients on ICS alone. The OR for total mortality was $1.22,95 \% \mathrm{Cl} 0.38-3.90$, reflecting 7 deaths in formoterol groups and 3 deaths in control groups respectively.

concLusions In patients with asthma using inhaled corticosteroids formoterol decreased the risk of asthma-related hospitalizations. There were too few asthma-related deaths and intubations to establish formoterol's relative impact on these outcomes.

INTRODUCTION Serious adverse effects of long acting $\beta$-agonists (LABAs) in patients with asthma have been suggested by randomized trials of salmeterol versus salbutamol by Castle et al. ${ }^{1}$, versus placebo in the SMART study by Nelson et al. ${ }^{2}$, and recently by systematic reviews of salmeterol and formoterol together ${ }^{3}$ or salmeterol alone $e^{4}$, both heavily influenced by the study of Nelson et al. ${ }^{2}$ These harmful effects have included severe asthma exacerbations requiring 
hospitalization, life threatening exacerbations requiring intubations, and asthma-related death. ${ }^{5}$ The above reports, however, included data from clinical settings in which inhaled steroids were not required in all patients. These patients were thus not treated according to current asthma management guidelines which have consistently recommended that LABAs should only be used in combination with inhaled corticosteroids (ICS) ${ }^{6,7}$ We have recently published a systematic review and meta-analysis looking specifically at the impact of LABAs (formoterol and salmeterol) on these most serious outcomes in population of patients with mandatory ICS use. ${ }^{8}$ Our results suggested that in such patients LABAs did not increase the risk of asthma-related hospitalizations and asthma related serious adverse events. Asthma-related deaths and intubations were too infrequent to establish LABA's relative effect on these outcomes.

In this paper we present data regarding formoterol use alone; data concerning salmeterol were recently published by Bateman et al. ${ }^{9}$ Some of the results of this study have been previously reported in an abstract. ${ }^{10}$

PATIENTS AND METHODS The details of methods were reported in the main manuscript. ${ }^{8}$ Key points are presented below.

Eligibility criteria All included studies had the following characteristics: treatment allocation by randomization; parallel control groups (cross-over studies excluded) with at least 12 weeks of treatment; blinding of patients and care-givers; acceptable follow-up of patients receiving study medication (outcome data for the full duration of planned treatment missing for $<20 \%$ of patients taking formoterol in trials $\leq 3$ month long, $<30 \%$ for over 3 months to less than 1 year long, $<40 \%$ for one year or longer). Eligible studies involved patients with asthma (excluding children younger than 12 years); all patients had to be receiving at least some ICS.

Intervention group Formoterol used regularly twice a day in addition to ICS. Formoterol and ICS could be delivered through single or through separate devices and patients could be receiving ICS as part of study medication or as non-study treatment required by the study protocol.

Control group Eligibility required that all patients in the control group used ICS, either as a part of study protocol (study medication) or as a required background therapy. The dose of ICS need not have been the same in intervention and control groups. We excluded studies in which control patients received regular LABA or regular short acting $\beta$-agonist. We also excluded studies in which the control group, in addition to ICS, received another asthma study medication (leukotriene receptor antagonist, theophylline).
Outcome measures Pre-specified outcomes included: asthma-related death; asthma-related non-fatal intubation and ventilation; asthma-related non-fatal hospitalization; asthma-related non-fatal serious adverse events (SAE); death from all causes (total death).

The pre-specified secondary outcomes were: total non-fatal intubation and ventilation; total non-fatal hospitalization; total non-fatal SAE; asthma-related death or intubation, and total death or intubation. We accepted the authors' or manufacturer's classifications of events as asthma-related or non-asthma-related.

Search strategy (identification of studies) We conducted searches of MEDLINE, EMBASE, ACPJC, and Cochrane (Central) as well as the AstraZeneca web site (http://www.astrazenecaclinicaltrials. com/article/511012.aspx). The search was updated up to April 2008. In addition, we asked the manufacturer of formoterol (AstraZeneca) to indicate all primary studies fulfilling our criteria but not previously identified.

Screening of titles/abstract and subsequently evaluation of full texts was done by two independent reviewers (Roman Jaeschke and either Jan Brożek, Filip Mejza, Parameswaran Nair or Wiktoria Leśniak).

Data extraction 2 reviewers independently extracted data from the articles and single manufacturer documents, reconciling differences by consensus. In addition to reviewing published data we asked corresponding authors and independently the manufacturer to provide information regarding the outcomes of interest and clarification of selected methodological details (concealment of randomization, blinded assessment and classification of outcomes, blinding of patients and care-givers, funding source). Final data on outcome measures were obtained from published reports, authors, and in each case sought from manufacturers. Discrepancies were resolved by contacting the study sponsor.

Analysis The data were analyzed using RevMan 5.0 (Cochrane Review Manager, Cochrane Collaboration, Oxford, UK) using the DerSimonian and Laird random effect model. ${ }^{11}$ Studies with no events were excluded in all analyses. In each case we analyzed the number of patients with a given outcome allowing only one outcome in a given category per patient. We decided, a priori, to restrict the formal statistical analyses to variables in which 6 or more events occurred. We used a random effects model to pool results from different studies as odds ratio (OR) [95\% confidence interval] (OR < 1.0 favors formoterol).

Heterogeneity was explored with the use of methods included in RevMan $\left(\mathrm{I}^{2}\right.$ and $\left.\chi^{2}\right)$ as well as by performing univariate and multivariable meta-regressions to investigate the following a priori hypotheses of factors potentially influencing effect size: dose of ICS used in the control 
group (similar dose of ICS to formoterol group or increased dose); daily dose of formoterol (9 micrograms per day vs. more); and use of ICS as part of study medications in single device with formoterol, in separate study devices, or as a non-study background medication. These analyses were performed using STATA (version 10.1). In the univariate and multivariable analysis, the criterion for statistical significance for each of the above analyses, performed using a t-test, was set a priori at $=0.10$.

For the estimation of number of patient-years on formoterol treatment we assumed that patients who did not complete the total duration of follow up for a given study received medication assigned by randomization for $50 \%$ of the study duration (i.e. for 12 weeks in 24-week studies).

RESULTS Our analysis included 16 studies identified in course of the process described previously. ${ }^{8}$ These publications are listed in Appendix A, the details about included studies are provided in Appendix C of the previous publication. ${ }^{8}$ All these studies used concealed randomization procedures, and in all cases assignment of 'asthma-related' to an event was done without knowledge of treatment used. All were sponsored by AstraZeneca. Two studies using formoterol fumarate (Foradil) were sponsored by Novartis or its predecessor (Ciba-Geigy). ${ }^{12,13}$ As we have not obtained complete data, those studies are not included in the analyses. However, the authors of primary reports of those studies, while reviewing safety, did not indicate either death or intubation as events in the study. Three additional studies fulfilled all inclusion criteria except that formoterol was administered to at least some patients only once daily (2003 Buhl, 2006 Rabe, 2006 Kuna; included in TABLE 1 and APPENDIX, but not considered in primary analysis). We have examined the impact of those 3 studies on the results using sensitivity analysis (including or excluding them in different combinations) and found no significant effect.

Among included studies 10 used similar doses of ICS in both groups, and six used higher dose of ICS in the control group than in those taking formoterol. For one study we excluded children below 12 years of age (stratified at randomization, study label '2005 O'Byrne'). Together this group of 16 studies included 10,638 participants (5,996 taking formoterol) and provided approximately 4,200 patient-years observation in formoterol groups.

In TABLE 1 we present the number of events in different outcome categories identified in all 16 studies included in the analysis (and in 3 studies not included). In TABLE 2 we present the results of meta-analysis of the same events in ten studies in which all patients were on similar dose of ICS, in those studies the difference between the groups are likely related to use of formoterol only. In TABLE 3 we show results of combined analysis of 6 studies, in which control group patients received more ICS than patients in the formoterol group; the difference between the groups is thus potentially related to both use of formoterol and to different ICS doses. In TABLE 4 we present the results of meta-analysis including all 16 studies.

Considering all 16 studies, there were 2 asthma-related deaths (both in formoterol groups, in two separate studies) and no asthma-related non-fatal intubations. One of the deaths occurred in a 35 year old female after an 8 day hospitalization for a severe asthma attack leading to intubation, ventilation, and nosocomial pneumonia with septic shock. The second death occurred in a 65 year old male who developed dyspnea and chest pain and died on admission to hospital despite attempts at cardio-pulmonary resuscitation. There were 8 additional deaths included in the "total mortality" category: 5 in the formoterol-ICS group: 2 categorized as suicide, 1 as pulmonary embolism, 1 as due to malignant metastatic disease and 1 as sudden death. 3 deaths in the ICS group were categorized as due to myocardial infarction, hypertrophic cardiomyopathy, and due to unknown cause respectively. The OR for total mortality was 1.22 (95\% CI 0.38-3.90) based on those 7 deaths in formoterol groups and 3 deaths in control groups; with one additional non-fatal intubation in each treatment category the OR for total mortality or intubation was 1.16 (95\% CI 0.38-3.57). There were too few events to analyze the relative incidence of most serious asthma-related events-deaths and intubations (2 deaths, both in formoterol groups, and zero asthma-related intubations). The differences between groups in other outcomes included less asthma related hospitalizations (OR 0.59, 95\% CI $0.37-0.93$ ) and less asthma-related serious adverse events (heavily influenced by hospitalizations, OR 0.58, 95\% CI 0.37-0.91; there were only 5 SAEs which were not hospitalizations) (TABLE 4, FIGURE). The trend towards reduction in the incidence of those outcomes was statistically significant in the subgroup of studies using the same dose of ICS in all patients (TABLE 2, Figure).

Exploration of heterogeneity There was no evidence against the homogeneity or consistency of treatment effects among studies for all outcomes using $=0.10$ level of significance.

Examination of the a priori hypotheses to explore or explain the residual heterogeneity (similarity of ICS dose in the formoterol and control group, daily dose of formoterol, and the mode of drug delivery investigated, each for several outcomes) revealed no statistically significant impact in all cases.

The results remained unchanged (no change in statistical significance and no important change in OR estimate) when we included 3 studies in which formoterol was administered to all or some patients only once daily (2003 Buhl, 2006 Rabe, 2006 Kuna). Combining fatal and non-fatal asthma related events (adding deaths to non-fatal hospitalizations and 


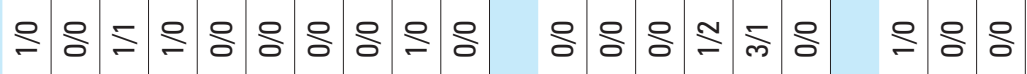

응응등응응응응응응응 응응응응으응 응응응

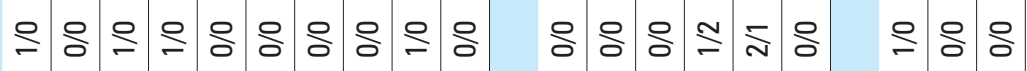

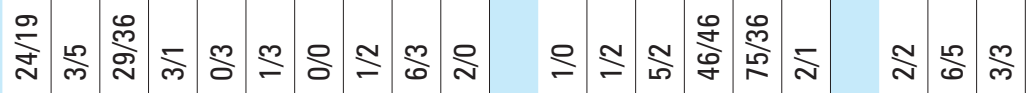

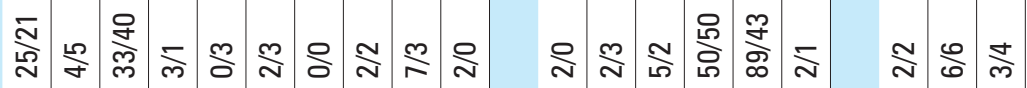

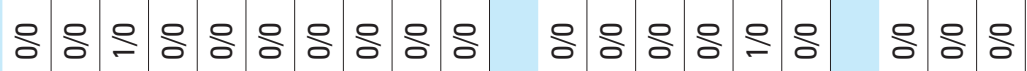

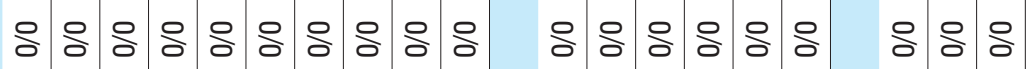
옹응옹응응응옹응응응 응응응응오응 응응응

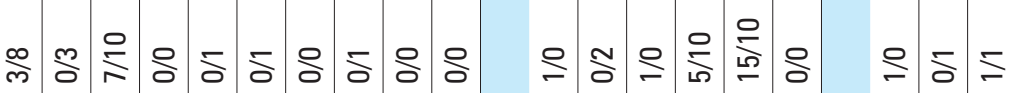

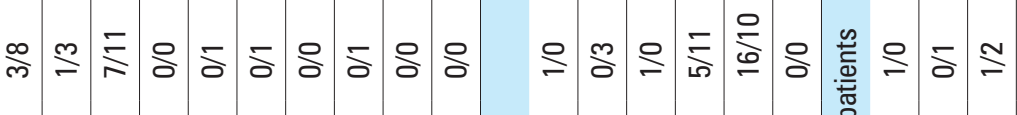

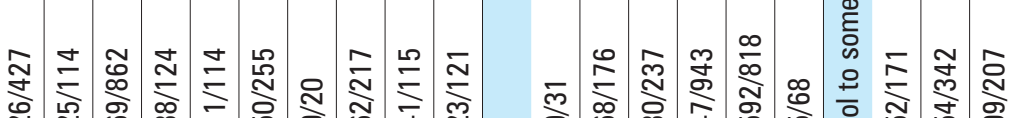

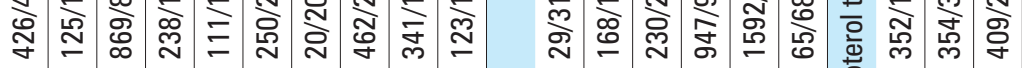


non-fatal SAE) also had no important effect on the results.

DISCUSSION This systematic review and meta-analysis of the effect of formoterol in combination with ICS on serious harmful effects in clinical trials of asthma did not show an increased risk for hospitalizations or serious adverse events; in fact the direction of effect appears beneficial. The relative effect on asthma related mortality and asthma related intubation and ventilation could not be assessed because of the very low number of those events. This contrasts with the report of Nelson et al. related to salmeterol (SMART study) $^{2}$ and the subsequent systematic review and the meta-analysis by Salpeter et al. which included both formoterol and salmeterol studies $^{3}$ - those authors reported increased risk of deaths and life threatening asthma experiences as well as an increase in the risk of asthma-related hospitalization (OR for hospitalizations in all studies combined 2.6, 95\% CI 1.6-4.3, for salmeterol studies OR 1.7, 95\% CI 1.1-2.7 and for formoterol studies OR 3.2, 95\% CI 1.7-6.0), ${ }^{3}$ all in settings in which ICS use was not required in all patients. Similarly, a recent Cochrane review of 62,630 patients in trials comparing salmeterol with placebo or salbutamol in which ICS use was again not mandated in all patients also found an increase in non-fatal serious adverse events related to use of salmeterol against placebo (among over 31,000 adults: OR 1.14, 95\% CI 1.01-1.28). ${ }^{4}$ Our own analyses, both when looking at combined LABA data ${ }^{8}$ and formoterol alone (this paper) did not confirm those findings in a setting mandating use of ICS.

We have discussed potential reasons for this difference in our previous paper. ${ }^{8}$ Our conclusions were that the differences were unlikely due to underlying asthma severity, shorter exposure to long acting $\beta$-agonist or differences between the randomized trials we examined (phase 3 studies) and the studies suggesting an increased mortality with LABA (post-marketing or phase 4 studies). The possibility that a lack of statistical power to detect a real difference was playing a role - after all both asthma related deaths and majority of all deaths occurred among patients on formoterol - can not be excluded. Our results do not exclude thus a relative increase in asthma related deaths, but show that the absolute increase in formoterol associated deaths or intubations from asthma in populations such as those participating in these trials, if it exists, is small ( 2 deaths and 0 non-fatal intubations in almost 6,000 patients receiving formoterol during more than 4,000 patient-year observations). Furthermore, in contrast to the Salpeter et al. ${ }^{3}$ and Cochrane ${ }^{4}$ meta-analyses our results exclude an important increase in asthma-related hospitalizations or serious adverse events, and strongly suggest the possibility of benefit of formoterol used with ICS on these outcomes.
We favor thus the remaining hypothesis explaining the differences in results - that the prognosis of asthma and the potential effects of LABA in general and formoterol in this case taken regularly are different among patients taking and not taking concomitant inhaled corticosteroid. This hypothesis suggests that ICS provides both protection against severe asthma deterioration and protection against the potential harmful actions of LABA by controlling components of airway inflammation, notably by decreasing airway eosinophil, lymphocyte and mast cell numbers. When LABA is used without concomitant ICS, this inflammatory response may not be adequately controlled, potentially leading to asthma worsening. ${ }^{14}$

The main limitations of this study are exclusion of children less than 12 years of age and inability to obtain full data from non AstraZeneca sponsored studies.

In summary, our systematic review evaluated the safety of adding formoterol to ICS and did not reveal convincing evidence of harm. We have extended previous reports that addition of LABA has no detrimental effect on the number of asthma-related hospitalizations and SAEs in patients receiving ICS. ${ }^{9,15}$ Due to the very low frequency of most serious events we have not excluded the possibility of a relative increase in deaths in patients receiving formoterol who are also using ICS. We have demonstrated that, in populations similar to those included in the eligible trials, any deleterious effect of formoterol on death or intubations in patients receiving ICS is - if it exists - small in absolute terms. The extent to which our results, taken together with evidence of symptomatic benefits of LABA ${ }^{16,17}$ are reassuring regarding the use of formoterol in patients receiving ICS may differ among physicians, patients, and policy-makers.

External funding This study was done without any external funding.

Contributions All co-authors participated in interpretation of data, and the development of the manuscript. The final version was seen and approved by all authors.

Roman Jaeschke contributed to all aspects of manuscript development. Paul M. O’Byrne participated in the designing the protocol, obtaining the study data; writing, reviewing and commenting on the manuscript. Filip Mejza, Jan Brożek and Wiktoria Leśniak participated in designing the protocol, searching the literature, selecting articles for inclusion, and reviewing the manuscript. Małgorzata Bała re-run all analyses and confirmed the results. Parameswaran Nair participated in designing the protocol, searching the literature, selecting articles for inclusion, extracting the data, planning the analysis, reviewing the manuscript and providing comments. Lehana Thabane and Ji Cheng participated in designing the protocol, extracting the data (Ji Cheng), 
TABLE 2 Safety of formoterol: analysis of data from 10 studies including 2965 patients taking formoterol and ICS (approximately 1600 patient-years) and 2369 control patients taking the same dose of ICS but without formoterol

\begin{tabular}{llll} 
Outcome & $\begin{array}{c}\text { Number of studies } \\
\text { with event }\end{array}$ & $\begin{array}{c}\text { Number of patients with events } \\
\text { (formoterol + ICS/ICS) }\end{array}$ & Odds ratio (95\% CI) \\
Asthma-related mortality & 1 & $1 / 0$ & - \\
\hline Asthma-related non-fatal intubation & 0 & $0 / 0$ & - \\
\hline Asthma-related non-fatal intubation or death & 1 & $1 / 0$ & $0.46(0.23-0.93)$ \\
\hline Asthma-related non-fatal hospitalization & 6 & $10 / 24$ & $0.45(0.23-0.90)$ \\
\hline Asthma-related non-fatal SAE & 6 & $11 / 25$ & - \\
\hline Total mortality & 4 & $4 / 0$ & - \\
\hline Total non-fatal intubation and ventilation & 1 & $0 / 1$ & - \\
\hline Total non-fatal intubation or death & 4 & $4 / 1$ & $0.87(0.61-1.22)$ \\
\hline Total non-fatal hospitalization & 9 & $69 / 72$ & $0.90(0.65-1.24)$ \\
\hline Total non-fatal serious adverse event & 9 & $78 / 78$ & \\
\hline
\end{tabular}

Abbreviations: See TABLE 1

TABLE 3 Safety of formoterol: data from 6 studies including 3031 patients taking formoterol and ICS (approximately 2500 patient-years) and 2273 patients taking higher dose of ICS but without formoterol

\begin{tabular}{llll} 
Outcome & $\begin{array}{c}\text { Number of studies } \\
\text { with event }\end{array}$ & $\begin{array}{c}\text { Number of patients with events } \\
\text { (formoterol + ICS/ICS) }\end{array}$ & $\begin{array}{c}\text { Odds ratio (95\% CI) } \\
\text { Asthma-related mortality }\end{array}$ \\
\hline Asthma-related non-fatal intubation & 0 & $1 / 0$ & - \\
\hline Asthma-related non-fatal intubation or death & 1 & $0 / 0$ & - \\
\hline Asthma-related non-fatal hospitalization & 5 & $1 / 0$ & $0.70(0.38-1.29)$ \\
\hline Asthma-related non-fatal SAE & 5 & $22 / 22$ & $0.69(0.38-1.26)$ \\
\hline Total mortality & 2 & $23 / 24$ & $0.71(0.13-3.91)$ \\
\hline Total non-fatal intubation and ventilation & 1 & $3 / 3$ & - \\
\hline Total non-fatal intubation or death & 2 & $1 / 0$ & $0.91(0.17-4.70)$ \\
\hline Total non-fatal hospitalization & 6 & $4 / 3$ & $1.07(0.81-1.42)$ \\
\hline Total non-fatal serious adverse event & 6 & $130 / 87$ & $1.07(0.82-1.40)$ \\
\hline
\end{tabular}

Abbreviations: See TABLE 1

TABLE 4 Safety of formoterol: data from all 16 studies including 5996 patients taking formoterol and ICS (approximately 4200 patient-years) and 4642 patients taking ICS but without formoterol

\begin{tabular}{llll} 
Outcome & $\begin{array}{c}\text { Number of studies with } \\
\text { event }\end{array}$ & $\begin{array}{l}\text { Number of patients with events } \\
\text { (formoterol + ICS/ICS) }\end{array}$ & $\begin{array}{c}\text { Odds ratio (95\% CI) } \\
\text { Asthma-related mortality }\end{array}$ \\
\hline Asthma-related non-fatal intubation & 0 & $2 / 0$ & - \\
\hline Asthma-related non-fatal intubation or death & 2 & $0 / 0$ & - \\
\hline Asthma-related non-fatal hospitalization & 11 & $2 / 0$ & $0.59(0.37-0.93)$ \\
\hline Asthma-related non-fatal SAE & 11 & $32 / 46$ & $0.58(0.37-0.91)$ \\
\hline Total mortality & 6 & $34 / 49$ & $1.22(0.38-3.90)$ \\
\hline Total non-fatal intubation and ventilation & 2 & $7 / 3$ & - \\
\hline Total non-fatal intubation or death & 6 & $1 / 1$ & $1.16(0.38-3.57)$ \\
\hline Total non-fatal hospitalization & 15 & $8 / 4$ & $0.98(0.79-1.23)$ \\
\hline Total non-fatal serious adverse event & 15 & $199 / 159$ & $1.00(0.81-1.23)$ \\
\hline
\end{tabular}

Abbreviations: see TABLE 1 
FIGURE Effects of formoterol on asthma-related serious adverse events among patients using intra-operative cell salvage

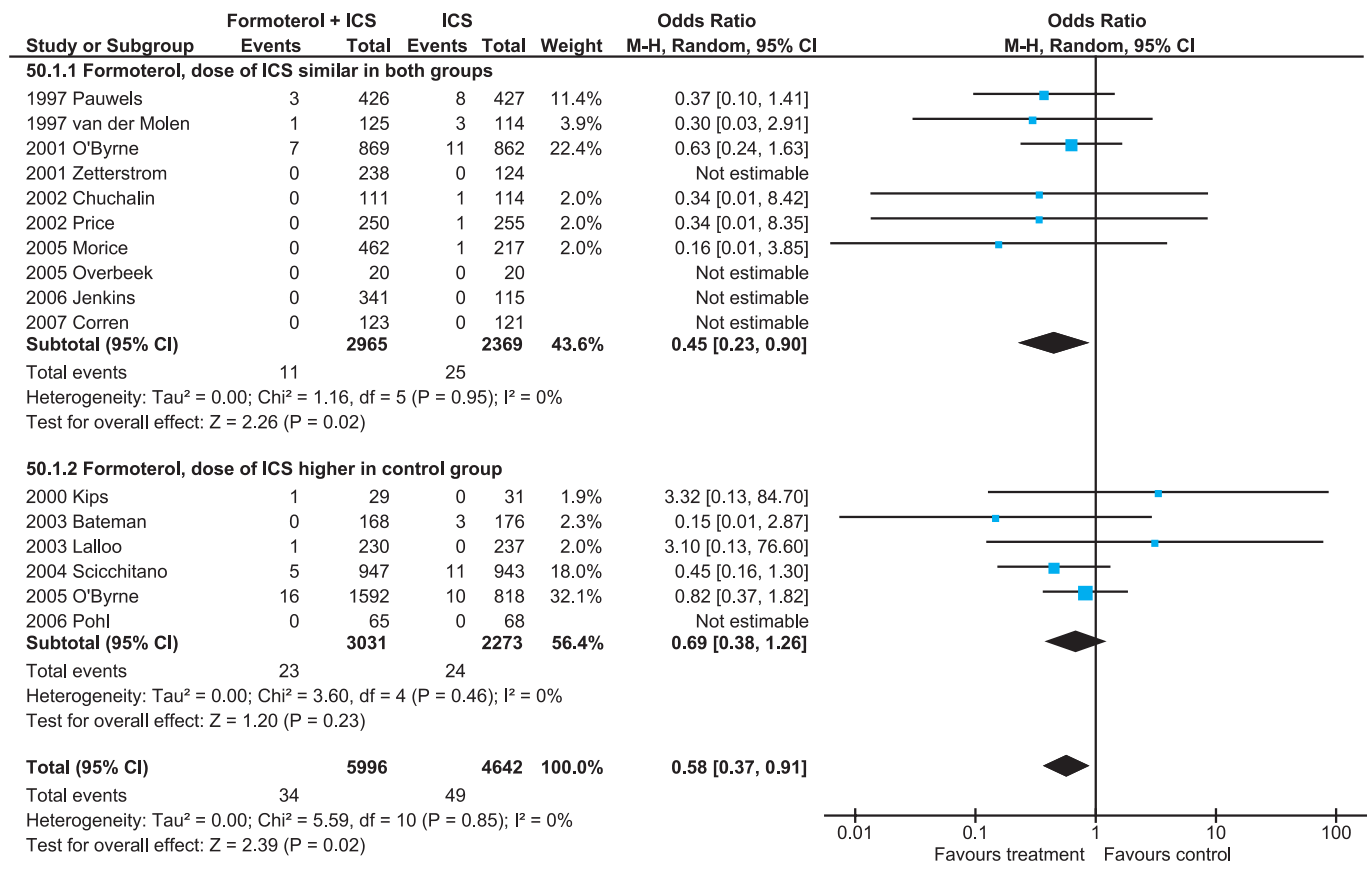

planning and performing the analysis, writing and reviewing the manuscript. Holger J. Schünemann participated in the designing the protocol, reviewing the manuscript and providing comments. Malcolm R. Sears participated in designing the protocol, writing the manuscript, reviewing the manuscript and providing comments. Gordon Guyatt participated in developing the protocol, planning and interpreting the analysis, writing the manuscript, reviewing the manuscript and providing comments.

\section{REFERENCES}

1 Castle W, Fuller R, Hall J, et al. Serevent nationwide surveillance study: comparison of salmeterol with salbutamol in asthmatic patients who re quire regular bronchodilator treatment. BMJ. 1993; 306: 1034-1037.

2 Nelson HS, Weiss ST, Bleecker ER, et al; SMART Study Group. The Salmeterol Multicenter Asthma Research Trial: a comparison of usual pharmacotherapy for asthma or usual pharmacotherapy plus salmeterol. Chest. 2006; 129: 15-26.

3 Salpeter SR, Buckley NS, Ormiston TM, et al. Meta-analysis: effect of long-acting $\beta$-agonists on severe asthma exacerbations and asthma-related deaths. Ann Intern Med. 2006; 144: 904-912.

4 Cates CJ, Cates MJ. Regular treatment with salmeterol for chronic asthma: serious adverse events. Cochrane Database of Systematic Reviews 2008; 3: CD006363.

5 Martinez FD. Safety of long-acting $\beta$-agonists - an urgent need to clear the air. N Eng J Med. 2005; 353: 2637-2639.

6 http://www.ginasthma.com/(date of last access 12/13/2007).

$7 \mathrm{http} / / /$ www.nhlbi.nih.gov/guidelines/asthma//date of last access 12/13/2007).

8 Jaeschke R, O'Byrne PM, Mejza F, et al. The safety of long acting $\beta$-agonists among patients with asthma using inhaled corticos teroids. Systematic review and meta-analysis. Am J Respir Crit Care Med. Articles in Press. Published on September 5, 2008 as doi:10.1164/rccm.200804-4940C

9 Bateman E, Nelson H, Bousquet J, et al. Meta-analysis: Effects of add ing salmeterol to inhaled corticosteroids on serious asthma-related events. Ann Intern Med. 2008; 149: 33-42.

10 Jaeschke R, Mejza F, Lesniak W, et al. The safety of formoterol among patients with asthma using inhaled corticosteroids. Abstract Book, ATS 2007: A57.

11 DerSimonian R, Laird N. Meta-analysis in clinical trials. Controlled Clin Trials. 1986; 7: 177-188

12 Mitchell C, Jenkins C, Scicchitano R, et al. Formoterol (Foradil) and medium-high doses of inhaled corticosteroids are more effective than high doses of corticosteroids in moderate-to severe asthma. Pulm Pharmacol Ther. 2003; 16: 299-306.

13 Fitz Gerald JM, Chapman KR, Della Cioppa G, et al. Sustained bronchoprotection, bronchodilatation, and symptom control during regular formoterol use in asthma of moderate or greater severity. J All Clin Immunol. 1999; 103: 427-435.

14 Mclvor RA, Pizzichini E, Turner MO, et al. Potential masking effects of salmeterol on airway inflammation in asthma. Am J Respir Crit Care Med. 1998; 158: 924-930.

15 Ernst P, Mclvor A, Ducharme FM, et al; Canadian Asthma Guideline Group. Safety and effectiveness of long-acting inhaled $\beta$-agonist bronchodilators when taken with inhaled corticosteroids. Ann Intern Med. 2006 145: 692-694.

16 Ni Chroinin M, Greenstone IR, Danish A, et al. Long-acting $\beta_{2}$-agonists versus placebo in addition to inhaled corticosteroids in children and adults with chronic asthma. Cochrane Database Syst Rev. 2005: CD005535.

17 Greenstone IR, Ni Chroinin MN, Masse V, et al. Combination of inhaled

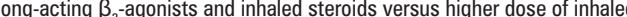
steroids in children and adults with persistent asthma. Cochrane Database Syst Rev. 2005: CD005533. 


\section{Studies with similar dose of ICS in all patients (10 studies)}

1997 Pauwels (37-3018) Pauwels RA, Lofdahl C-G, Postma DS, et a Effect of inhaled formoterol and budesonide on exacerbations of asthma. N Engl J Med. 1997; 337: 1405-1411.

1997 Van der Molen (37-3008) van der Molen T, Postma DS, Turne $\mathrm{MO}$, et al. Effects of the long acting $\beta$-agonist formoterol on asthma contro in asthmatic patients using inhaled corticosteroids. The Netherlands and Canadian Formoterol Study Investigators. Thorax. 1997; 52: 535-539

2001 O'Byrne (SD-037-0345) O'Byrne PM, Barnes PJ, Rodriguez-Roi$\sin \mathrm{R}$, et al. Low dose inhaled budesonide and formoterol in mild persistent asthma: the OPTIMA randomized trial. Am J Respir Crit Care Med. 2001 164: 1392-1397.

2001 Zetterstom (SD-039-0349) Zetterstrom 0, Buhl R, Mellem H et al. Improved asthma control with budesonide/formoterol in a single inhaler, compared with budesonide alone. Eur Resp J. 2001; 18: 262-268.

2002 Chuchalin (MA-037-0001) Chuchalin AG, Svensson K, Stahl E et al. A health-related quality-of-life comparison of formoterol (Oxis) Turbuhaler plus budesonide (Pulmicort) Turbuhaler with budesonide Turbuhaler alone and noncorticosteroid treatment in asthma: a randomized clinical study in Russia. EPOCH Study Group. Respiration. 2002; 69: 427-433.

2002 Price (BU-543-0681B) Price D, Dutchman D, Mawson A, et al. FLOW (Eformoterol in the management of mild asthma-eformoterol Turboinhaler with budesonide Turbohaler) research group. Early asthma control and maintenance with eformoterol following reduction of inhaled corticosteroid dose. Thorax. 2002; 57: 791-798.

2005 Overbeek (BN-00P-0059) Overbeek SE, Mulder PG, Baelemans SM, et al. Formoterol added to low-dose budesonide has no additional antiinflammatory effect in asthmatic patients. Chest. 2005; 128: 1121-1127.

2005 Morice (SD-039-0681) Morice AH, Osmanliev D, Arheden L, et al. Therapeutic equivalence of a novel budesonide/formoterol pMDI versus budesonide/formoterol Turbuhaler $\AA$ in adolescents and adults with asthma. J Allergy Clin Immunol. 2005; 115; S2, Abst 8.

2006 Jenkins (SD-039-0689) Jenkins C, Kolarikova R, Kuna P, et al. Ef ficacy and safety of high-dose budesonide/formoterol (Symbicort) com pared with budesonide administered either concomitantly with formoterol or alone in patients with persistent symptomatic asthma. Respirology. 2006; 11: 276-286.

2007 Corren (SD-039-0716) Corren J, Korenblat PE, Miller CJ, et al. Twelve-week, randomized, placebo-controlled, multicenter study of the ef ficacy and tolerability of budesonide and formoterol in one metered-dose in haler compared with budesonide alone and formoterol alone in adolescents and adults with asthma. Clin Ther. 2007: 29: 823-843.

\section{Studies with increased dose of ICS in the control group ( 6 studies)}

2000 Kips (37-3041) Kips JC, O'Connor BJ Inman MD, et at. A long-term study of the anti-inflammatory effect of low-dose budesonide plus formoterol versus high-dose budesonide in asthma. Am J Respir Crit Care Med. 2000; 161: 996-1001.

2003 Bateman (SD-039-0618) Bateman RD, Bantje TA, Gomes M et al. Combination therapy with a single inhaler budesonide/formotero compared with high dose fluticasone proprionate alone in patients with moderate persistent asthma. Am J Repir Med. 2003; 2: 275-281.

2003 Lalloo (SD-039-0348) Lalloo UG, Matolepszy J, Kozma D, et al. Budesonide and formoterol in a single inhaler improves asthma control compared with increasing the dose of corticosteroid in adults with mild-to-moderate asthma. Chest. 2003, 123: 1480-1487.

2004 Scicchitano (SD-039-0668) Scicchitano R, Aalbers R, Ukena D, et al. Efficacy and safety of budesonide/formoterol single inhaler therapy versus a higher dose of budesonide in moderate to severe asthma. Curr Med Res Opin. 2004; 20: 1403-1418.

2005 0'Byrne (SD-039-0673) O'Byrne PM, Bisgaard H, Godard PP, et al. Budesonide/formoterol combination therapy as both maintenance and reliever medication in asthma. Am J Respir Crit Care Med. 2005; 171 $129-136$.

2006 Pohl (BA-039-0001) Pohl WR, Vetter N, Zwick H, Hrubos W. Adjustable maintenance dosing with budesonide/formoterol or budesonide: Double-blind study. Respir Med. 2006: 100: 551-560.

\section{Studies with once daily dose of formoterol in some patients}

2003 Buhl (SD-039-0666) (ICS dose the same in control group) Buh $\mathrm{R}$, Creemers JPHM, Vondra V, et al. Once-daily budesonide/formoterol in a single inhaler in adults with moderate persistent asthma. Respir Med. 2003: 97: 323-930.

2006 Rabe (SD-039-0667) (ICS dose higher in control group) Rabe KF, Pizzichini $E$, Stallberg B, et al. Budesonide/formoterol in a single inhaler for maintenance and relief in mild-to-moderate asthma - A randomized, double-blind trial. Chest. 2006; 129: 246-256.
2006 Kuna (SD-039-0665) (ICS dose the same in the contro group) Kuna $\mathrm{P}$, Creemers JP, Vondra V, et al. Once-daily dosing with budesonide/formoterol compared with twice-daily budesonide/formoterol and once-daily budesonide in adults with mild to moderate asthma. Respir Med. 2006; 100: 2151-2159.

\section{CONFLICT OF INTEREST}

Roman Jaeschke received honoraria for lectures from AstraZeneca Merck Sharp \& Dohme, Boehringer Ingelheim, and GlaxoSmithKline, and travel support from Boehringer Ingelheim and GlaxoSmithKline. He is a deputy editor of a journal funded in part by industry advertisement including manufactures of the drugs that are the subject of this review.

Paul M. O'Byrne has been on Advisory boards for AstraZeneca, Biolipox GlaxoSmithKline, Nycomed, Ono Pharma, Topingen, and Resistencia, and has received lecture fees from these pharmaceutical companies as well as from Chiesi. He holds industry-sponsored grants fron AstraZeneca, Altana Chiesi, Biolipox, Boehringer, GlaxoSmithKline, Medimmune, Merck, Pfizer, and Wyeth.

Parameswaran Nair holds investigator-initiated grants from GlaxoSmithKline Canada, Sepracor Inc., and Topigen Inc. and two investigator-initiated grants from a Firestone-Pharmaceutical Industry Strategic Collaboration. In the past 3 years, he has received honoraria from Merck Frosst and GlaxoSmithKline for academic lectures. He serves on the Health Canada Scientific Advisory Committee for Respiratory \& Allergy Therapies. His research group has a patent on a sputum filtration device.

Jan Brożek is a journal editor and receives a salary from a clinical journal where various drugs are advertised, including those that are the subject of this systematic review. He received an honorarium from GlaxoSmithKline. Lehana Thabane is currently a statistician consulting for GlaxoSmithKline

In the past three years, Dr. Schünemann received no personal payments for service from the pharmaceutical industry. He received research grants and - until April 2008 - fees and/or honoraria that were deposited into research accounts from AstraZeneca, Chiesi Foundation, Lily, Pfizer, Roche and UnitedBioSource for development or consulting regarding quality of life instruments for chronic respiratory diseases or as lecture fees related to the methodology of evidence based practice guideline development and/or research methodology. He is documents editor and methodologist for the American Thoracic Society. Institutions or organizations that he is affiliated with likely re ceive funding from for-profit sponsors that are supporting infrastructure and research that may serve his work

Malcolm R. Sears has received research funding and/or an honorarium for lectures and consultations from AstraZeneca, GlaxoSmithKline, Merck, Nycomed, and Schering Plough, received grants over the last 5 years from AstraZeneca Boehringer Ingelheim, GlaxoSmithKline, and Merck Frosst Canada, and holds a chair in Respiratory Epidemiology jointly endowed by AstraZeneca and McMaster University.

Gordon Guyatt received funding from the following pharmaceutical companies to carry out research projects: Lotte and John Hecht Foundation Bristol-Myers Squibb, and Pfizer Inc. He is currently acting as a consultant and received honoraria from University of Illinois Pharmacy Administration, Eli Lilly Canada Inc. 